BIOMEDICAL AND BIOSOCIAL ANTHROPOLOGY
$\begin{gathered}\text { Official Journal of the International Academy } \\ \text { of Integrative Anthropology } \\ \text { journal homepage: http://bba-journal.com }\end{gathered}$

\title{
Safety of transcranial magnetic stimulation in patients with multiple sclerosis
}

Malakhov V. O., Gaponov P. K.

Department of Medical rehabilitation, sports medicine and medical physicaleducation of Medical Academy of Post-graduate Education, Kharkiv, Ukraine

\section{ARTICLE INFO}

Received: 11 January 2021

Accepted: 12 February 2021

UDC: $616.832-004: 615.8: 615.847 .8$

\section{CORRESPONDING AUTHOR}

e-mail: Ifk@med.edu.ua

Malakhov V. O.
Multiple sclerosis is a demyelinating, degenerative disease that is associated with increasing disability. Multiple sclerosis is one of the main reasons for the permanent disability of young people. To improve the quality of life there is a need for comprehensive rehabilitation measures, especially in the initial stages of the disease. In recent years, there are new techniques of non-invasive neuromodulation that can improve the patient's recovery. Methods that can affect neuroplasticity include transcranial magnetic stimulation. The aim of this study was to assess the safety and potential for adverse effects of transcranial magnetic stimulation during and after a session in patients with multiple sclerosis. The results were obtained by examining 80 patients with multiple sclerosis (diagnosed according to the criteria of McDonald et al., 2017), who received a course of rTMS. All patients received disease-modifying therapy drugs, taking into account the recommendations of the European MS Treatment Guidelines Released. For the purpose of noninvasive neuromodulation in the process of treatment and rehabilitation, rTMS was used. The course of treatment was performed on a MagVenture device, MagPro X100 and an 8-shaped inductor (coil). All patients were tested using a safety questionnaire and selected according to the indications and contraindications of rTMS. Depending on the leading clinical manifestations, different protocols for rTMS were used. Protocols with high-frequency stimulation of DLPFC zones and primary motor cortex, M1 zone were selected. Statistical data processing was performed using the licensed office suite Microsoft Excel 2013. In some patients with multiple sclerosis (35.0\%) during rTMS, during the session or the day after the session, and in some cases later, adverse events were noted. Depending on the stimulation zone, the frequency of their occurrence was different. When using high-frequency rTMS of the primary motor cortex, adverse events were observed in $32.5 \%$ of cases in the form of discomfort in the area of the procedure, headache, changes/decrease in hearing, neck pain, episodic paroxysmal anxiety. When using high-frequency rTMS DLPFK, adverse events were observed in $33.8 \%$ of cases in the form of discomfort in the area of the procedure, headache, hearing loss/transient changes, transient changes in cognitive function, neck pain, high blood pressure, shooting pain in the temporal area on the stimulation side. According to our observations, adverse events were observed not only during rTMS, some of them continued to be observed during the day after the session and more. Thus, TMS occupies an important place in the process of non-drug rehabilitation of patients with multiple sclerosis. The safety of TMS includes careful selection of patients in accordance with the criteria of indications and contraindications of the procedure, the patient's consent to TMS, the choice of stimulation protocol with personalized selection of parameters, prevention of side effects and monitoring of the patient during TMS.

Keywords: multiple sclerosis, rhythmic transcranial magnetic stimulation, non-invasive neuromodulation, adverse events.

\section{Introduction}

Multiple sclerosis is a chronic, autoimmune demyelinating, neurodegenerative disease of the nervous system, which is manifested by diffuse organic neurological symptoms, which has a progressive course and affects 
people mostly young, able-bodied age. Multiple sclerosis is a complex, heterogeneous disease associated with increasing disability [16]. According to the WHO, among neurological diseases, multiple sclerosis is one of the main causes of persistent disability of young people. Multiple sclerosis has a wide range of clinical manifestations. Despite the availability of advanced treatments that modify the disease, as well as symptomatic treatments that can reduce the activity and progression of the disease, there is a need for comprehensive rehabilitation measures to improve quality of life [8]. In recent years, in addition to improving the existing arsenal of neurorehabilitation methods (exercise therapy, kinesiotherapy, physiotherapy), there are new techniques that can improve the patient's recovery [7]. The latest methods include transcranial magnetic stimulation (TMS). The peculiarity of the TMS method is its non-invasiveness, safety and ease of use. All these qualities and the possibility of differentiated use allow the use of TMS in the clinic of rehabilitation treatment and become an important component of active drug and nondrug rehabilitation of patients with multiple sclerosis [9]. In 2009, updated recommendations on ethical standards and safety of TMS in clinical practice were published [13]. The safety of TMS includes the selection of patients in accordance with the criteria of indications and contraindications for the procedure, the patient's consent to TMS, the choice of stimulation protocol with the selection of parameters, prevention and treatment of side effects and monitoring of the patient during TMS [11]. But even the maximum compliance with all international guidelines for the safety of TMS and careful selection of patients does not exclude the risk of adverse events.

The aim of the study was to evaluate the safety and possibility of adverse effects of transcranial magnetic stimulation during and after the session in patients with multiple sclerosis.

\section{Materials and methods}

The results were obtained by examining 80 patients with multiple sclerosis (diagnosed according to the criteria of McDonald et al., 2017), who received a course of rTMS. The clinical picture in patients with multiple sclerosis was dominated by motor and coordination disorders, moderate cognitive impairment, pathological fatigue, depressive disorders (including those caused by taking DMT drugs of the interferon series).

All patients received disease-modifying therapy drugs, taking into account the recommendations of the European MS Treatment Guidelines Released - drugs of the 1st (interferon beta 1- $\beta$, interferon beta 1- $\alpha$, glatiramer acetate, teriflunomide) or 2nd link (mitoxantrone, okrelizumab, alemtuzumab, cladribine) depending on the type of course, in combination with pulse therapy with methylprednisolone in case of exacerbation [10].

For the purpose of noninvasive neuromodulation in the process of treatment and rehabilitation, rTMS was used.
The course of treatment was performed on a MagVenture device, MagPro X100 and an 8-shaped inductor (coil). All patients were tested using a safety questionnaire and selected according to the indications and contraindications of rTMS. Depending on the leading clinical manifestations, different protocols for rTMS were used, which could be combined in one patient during a course of non-invasive neuromodulation. Protocols with high-frequency stimulation of DLPFC and primary motor cortex zones, M1 zone $(D, S)$ with frequency $10 \mathrm{~Hz}$, amplitude of $90-100 \%$ of WWII, duration of 10 sessions, from 1600 to 2000 stimuli per session were selected.

The procedures of this study are in line with the ethical standards of the 1975 Declaration of Helsinki, as revised in 2008, and national legislation. Informed consent to participate in the study was discussed and signed by all study participants. Meeting of the Commission on Ethics and Deontology (Minutes № 7 B of July 19, 2019) of the SI "Institute of Neurology, Psychiatry and Narcology of the National Academy of Medical Sciences of Ukraine".

Statistical data processing was performed using the licensed office suite Microsoft Excel 2013.

\section{Results}

During our course of rTMS in patients with multiple sclerosis, such adverse events as epileptic seizures, syncope, and hypomanic states described in the works of other researchers were not observed. However, in 28 patients $(35.0 \%)$, during the session or the day after the session, and in some cases later, we noted other adverse events. Depending on the stimulation zone, the frequency of their occurrence was different (Table 1).

When using high-frequency rTMS of the primary motor cortex, adverse events were observed in $32.5 \%$ of cases in the form of discomfort in the area of the procedure, headache, changes/decrease in hearing, neck pain, episodic paroxysmal anxiety. The most common were headache and neck pain (18.8\% of cases), discomfort in the area of stimulation $(10.0 \%)$. In a smaller number of cases, there was a transient change in hearing $(2.5 \%)$, episodic paroxysmal anxiety (1.25\%), which is probably not associated with the effects of stimulation.

When using high-frequency rTMS DLPFC adverse events were observed in $33.8 \%$ of cases in the form of discomfort in the area of the procedure, headache, hearing loss/ transient, transient changes in cognitive function, neck pain, high blood pressure, shooting pain in the temporal area on the stimulation side. The most common were headache and neck pain (22.5\% of cases) and discomfort in the area of stimulation ( $5 \%$ ).

In a smaller number of cases, there was a transient change in hearing (1.3\%), a transient change in cognitive functions (1.3\%), an increase in blood pressure (1.3\%), shooting pains in the temporal area (2.5\%).

Depending on the predominance of neurological symptoms, patients used stimulation protocols of both the 
Table 1. Adverse effects of rTMS depending on the stimulation zone $(n=80)$.

\begin{tabular}{|c|c|c|}
\hline Adverse effect & $\begin{array}{l}\text { High-frequency rTMS } \\
\text { of the primary motor } \\
\text { cortex of the dominant } \\
\text { hemisphere (zone M1) }\end{array}$ & $\begin{array}{l}\text { High-frequency rTMS } \\
\text { DLPFC of the } \\
\text { dominant hemisphere }\end{array}$ \\
\hline Epileptic seizures & Not observed & Not observed \\
\hline Syncope & Not observed & Not observed \\
\hline $\begin{array}{l}\text { Development of } \\
\text { hypomanic episode }\end{array}$ & Not observed & Not observed \\
\hline $\begin{array}{l}\text { Transient change in } \\
\text { hearing }\end{array}$ & $2(2.5 \%)$ & $1(1.3 \%)$ \\
\hline $\begin{array}{l}\text { Transient change of } \\
\text { cognitive functions }\end{array}$ & Not observed & $1(1.3 \%)$ \\
\hline $\begin{array}{l}\text { Headache, neck } \\
\text { pain }\end{array}$ & $15(18.8 \%)$ & $18(22.5 \%)$ \\
\hline $\begin{array}{l}\text { Discomfort in the } \\
\text { area of stimulation }\end{array}$ & $8(10.0 \%)$ & $4(5.0 \%)$ \\
\hline $\begin{array}{l}\text { Episodic paroxysmal } \\
\text { anxiety }\end{array}$ & $\begin{array}{c}1(1.3 \%) \text {, not } \\
\text { associated with } \\
\text { stimulation effects }\end{array}$ & Not observed \\
\hline $\begin{array}{l}\text { Increased blood } \\
\text { pressure }\end{array}$ & Not observed & $\begin{array}{l}1(1.3 \%) \text {, probably of } \\
\text { psychogenic origin }\end{array}$ \\
\hline $\begin{array}{l}\text { Shooting pains in the } \\
\text { temporal area on the } \\
\text { side of stimulation }\end{array}$ & Not observed & $2(2,5 \%)$ \\
\hline
\end{tabular}

Table 2. The duration of the adverse event during or after the rTMS session $(n=80)$.

\begin{tabular}{|c|c|c|c|}
\hline Adverse effect & $\begin{array}{c}\text { Disappeared } \\
\text { during the } \\
\text { session }\end{array}$ & $\begin{array}{c}\text { Observed in } \\
\text { the first 24 } \\
\text { hours after the } \\
\text { session }\end{array}$ & $\begin{array}{c}\text { More than } \\
24 \text { hours }\end{array}$ \\
\hline $\begin{array}{c}\text { Transient change in } \\
\text { hearing }\end{array}$ & $3(100 \%)$ & - & - \\
\hline $\begin{array}{c}\text { Transient change of } \\
\text { cognitive functions }\end{array}$ & $1(100 \%)$ & - & - \\
\hline Headache, neck pain & $24(72.7 \%)$ & $8(24.24 \%)$ & $1(3.0 \%)$ \\
\hline $\begin{array}{c}\text { Discomfort in the area } \\
\text { of stimulation }\end{array}$ & $12(100 \%)$ & - & - \\
\hline $\begin{array}{c}\text { Episodic paroxysmal } \\
\text { anxiety }\end{array}$ & $\begin{array}{c}1(100 \%), \text { not } \\
\text { associated with } \\
\text { stimulation } \\
\text { effects }\end{array}$ & - & - \\
\hline $\begin{array}{c}\text { Increased blood } \\
\text { pressure }\end{array}$ & - & $1(100 \%)$ & - \\
\hline $\begin{array}{c}\text { Shooting pains in the } \\
\text { temporal area on the } \\
\text { side of stimulation }\end{array}$ & $2(100 \%)$ & - & - \\
\hline
\end{tabular}

motor cortex and DLPFC.

In some patients, a combination of several adverse events was observed: discomfort in the area of stimulation, shooting pains in the temporal area of the face on the side of stimulation; episodic paroxysmal anxiety, increased blood pressure; headache, transient hearing loss, discomfort in the area of stimulation, shooting pains in the temporal area of the face on the side of stimulation, headache or pain in the cervical spine. The most common combination of side effects: discomfort in the area of stimulation, headache or pain in the cervical spine. Adverse events were observed mainly in the first sessions of rTMS, especially a combination of several adverse events. Their number and intensity decreased during the course of TMS until complete cessation.

When side effects appear in the form of unpleasant sensations in the area of stimulation or pain, we stopped the stimulation, and in some we reduced the intensity of the stimulus until the cessation of these sensations. To reduce possible hearing impairment during the rTMS session, the patient was offered to use earplugs.

According to our observations, adverse events were observed not only during TMS, some of them continued to be observed during the day after the session and more (Table 2).

Thus, headache or neck pain persisted during the day in $24.2 \%$ of the total number of headache cases, and in some cases $(3.0 \%)$ for more than a day. Sex analysis of the data showed that most cases of headache and neck pain were recorded in women.

\section{Discussion}

There is a need for comprehensive rehabilitation measures to improve the quality of life [3]. In recent years, the method of TMS is increasingly used and therefore more and more attention is paid to the possibility of side effects during this procedure. The literature provides data on the occurrence of adverse events: paroxysmal states, headache, neck pain, hearing changes, discomfort in the area of stimulation, transient cognitive disorders, anxiety and others. All authors agree that the frequency of adverse events in most cases depends on the careful selection of patients, the characteristics of treatment protocols, dynamic monitoring of the patient during the session and on the first day [1]. In the process of selecting patients for noninvasive neurostimulation, it is necessary to take into account the physical features of the TMS method [5]. Therefore, the absolute contraindications to use were the presence in the patient's body of conductive or magnetic materials (dental and cochlear implants, insulin pumps, pacemakers, defibrillators, vagus nerve stimulators, metal suture material, plates and others) [6]. The presence in patient cardiovascular, infectious or metabolic diseases of the brain, alcohol or chemical dependence, the presence of a history of stroke [4, 7], surgery, trauma, syncope, taking drugs that reduce the seizure threshold (for example: high doses neuroleptics and tricyclic antidepressants), pregnancy [15], childhood are not absolute contraindications for TMS, but can significantly increase the risk of adverse events $[13,15]$. To minimize such effects, all patients selected for the study were asked to complete a questionnaire taking into account all these questions, adapted from our recommendations on ethical standards and safety of TMS in clinical practice $[11,13]$.

In addition to the generally accepted questions, we 
introduced the question of the presence of dominance of the right or left hand. This is due to the results of the study "Approach to motivation in the human cerebral cortex" published in Philosophical Transactions of the Royal Society B: Biological Sciences. According to a new theory called the "sword and shield hypothesis", how we perform actions with our hands determines how emotions are organized in our brain. Work is important for the modern treatment of anxiety and depression. The technique used in the study included mild electrical or magnetic stimulation of the left hemisphere of the brain to stimulate emotions. Right-handers, who influenced the left hemisphere, felt a strong rise in positive emotions. As well as left-handers, who stimulated the right hemisphere. But when lefthanders affected the left hemisphere, and right-handers on the right, in some cases there was no change in the experience of emotions, and in other cases the opposite effect was observed: the person felt less emotion [2]. Therefore, treatment using standard approaches can be dangerous for left-handed patients. In our study, when filling out the questionnaire, only one left-handed patient was identified, which required correction of the protocol to take into account changes in the dominant hemisphere.

According to the results of our study during rTMS in 28 $(35.0 \%)$ patients, during the session or on the first day, and sometimes later, various adverse events were observed. According to the literature in other studies, this level of adverse events was also observed [15]. All researchers emphasize that the frequency of their development depended, in most cases, on the stimulation zone [1]. During stimulation of the primary motor cortex, patients with more frequent adverse events were cases of discomfort in the area of stimulation in the form of itching, tingling, as well as headache, hearing loss/change and neck pain, and the frequency of these cases was $32.5 \%$. Patients with multiple sclerosis most often had headache and neck pain (18.75\% of cases) and discomfort in the

\section{References}

[1] Bakulin, I. S., Pojdasheva, A. G., Lagoda, D. Yu., Evdokimov, K. M., Zabirova, A. H., Suponeva, N. A., \& Piradov, M. A. (2019). [Safety and tolerability of various high-frequency rhythmic transcranial magnetic stimulation protocols]. Ульяновский медико-биологический журнал - Ulyanovsk medical and biological journal, (1), 26-37. doi: 10.34014/2227-1848-20191-26-37

[2] Brookshire, G., \& Casasanto, D. (2018). Approach motivation in human cerebral cortex. Philosophical Transactions of the Royal Society B: Biological Sciences, 373(1752), 20170141. doi: 10.1098/rstb.2017.0141

[3] Chernikova, L. А. (2016). Восстановительная неврология: инновационные технологии в нейрореабилитации [Reconstructive neurology: innovative technologies in neurorehabilitation]. Москва: МИA - Moscow: MIA.

[4] Chervyakov, A. V., Pojdasheva, A. G., Nazarova, M. A., Gnezdickij, V. V., Suponeva, N. A., CHernikova, L. A., \& Piradov, М. А. (2015). Навигационная ритмическая транскраниальная магнитная стимуляция в постинсультной реабили- stimulation area (10.0\%). During DLPFC stimulation, with an incidence of $33.75 \%$, there were cases of discomfort in the area of the procedure, headache, hearing loss/ decrease, transient change in cognitive function, neck pain, high blood pressure, shooting pain in the temporal area on the side of stimulation. The most common of these were cases of headache and neck pain (22.5\% of cases), possibly due in part to an awkward tense posture. According to our observations, it was noted that most cases of headache and neck pain were recorded in women.

We also observed the possibility of a combination of several adverse events, mainly in the first sessions of rTMS. The most common of these were discomfort in the area of stimulation, headache or pain in the cervical spine. In the available literature, we did not find the results of the analysis of a combination of negative phenomena. In some cases of discomfort in the area of stimulation or pain, we stopped the stimulation or reduced the intensity of the stimulus, which led to the complete cessation of these sensations. Also, the use of earplugs during stimulation was mandatory, which was recommended by a group of experts [12]. Most often, in patients with multiple sclerosis, adverse events occurred immediately after the end of the rTMS session, but sometimes continued for the first 24 hours or more, namely headache, neck pain and high blood pressure.

\section{Conclusion}

TMS, as a method of non-invasive neuromodulation, plays an important role in the process of non-drug rehabilitation of patients with multiple sclerosis. The safety of TMS includes careful selection of patients in accordance with the criteria of indications and contraindications of the procedure, the patient's consent to TMS, the choice of stimulation protocol with personalized selection of parameters, prevention of side effects and monitoring of the patient during TMS.

тации: рандомизированное слепое плацебоконтролируемое исследование [Navigational rhythmic transcranial magnetic stimulation in post-stroke rehabilitation: a randomized, blind, placebo-controlled trial]. Анналы клинической и экспериментальной неврологии - Annals of Clinical and Experimental Neurology, 9(4), 32-38.

[5] Di Lazzaro, V. (2013). Biological effects of non-invasive brain stimulation. Handb. Clin. Neurol., (116), 367-374. doi: 10.1016/ B978-0-444-53497-2.00030-9

[6] Eldaief, M. C., Press, D. Z., \& Pascual-Leone, A. (2013). Transcranial magnetic stimulation in neurology: a review of established and prospective applications. Neurology: Clinical Practice, 3(6), 519-526. doi: 10.1212/ 01.CPJ.0000436213.11132.8e

[7] Hatem, S. M., Saussez, G., Della Faille, M., Prist, V., Zhang, X., Dispa, D., \& Bleyenheuft, Y. (2016). Rehabilitation of motor function after stroke: a multiple systematic review focused on techniques to stimulate upper extremity recovery. Frontiers in human neuroscience, 10, 442. doi: 10.3389/ 
fnhum.2016.00442

[8] Hauser, S. L., \& Cree, B. A. C. (2020). Treatment of Multiple Sclerosis: A Review. The American Journal of Medicine, 133(12), 1380-1390.e2. doi: 10.1016/j.amjmed.2020.05.049

[9] Leocani, L., Chieffo, R., Gentile, A., \& Centonze, D. (2019). Beyond rehabilitation in MS: Insights from non-invasive brain stimulation. Multiple Sclerosis Journal, 25(10), 1363-1371. doi: $10.1177 / 1352458519865734$

[10] Muratova, T. M., Nehrych, T. I., Voloshyna, N. P., Mialovytska, O. A., Pashkovskyi, V. M., \& Khubetova, I. V. (2020). Розсіяний склероз в Україні: персоналізована стратегія лікування [Multiple sclerosis in Ukraine: a personalized treatment strategy]. Здоров'я України - Health of Ukraine, (2), 14-16.

[11] Najib, U., \& Horvath, J. C. (2014). Transcranial magnetic stimulation (TMS) safety considerations and recommendations. In Transcranial magnetic stimulation (pp. 15-30). Humana Press, New York, NY.

[12] Rossi, S., Antal, A., Bestmann, S., Bikson, M., Brewer, C., Brockmoller, J., ... \& Hallett, M. (2020). Safety and recommendations for TMS use in healthy subjects and patient populations, with updates on training, ethical and regulatory issues: expert guidelines. Clinical Neurophysiology, (132),
269-270. doi: 10.1016/j.clinph.2020.10.003

[13] Rossi, S., Hallett, M., Rossini, P. M., Pascual-Leone, A., \& Safety of TMS Consensus Group. (2009). Safety, ethical considerations, and application guidelines for the use of transcranial magnetic stimulation in clinical practice and research. Clinical neurophysiology, 120(12), 2008-2039. doi: 10.1016/j.clinph.2009.08.016

[14] Sayar, G. H., Ozten, E., Tufan, E., Cerit, C., Kagan, G., Dilbaz, N., \& Tarhan, N. (2014). Transcranial magnetic stimulation during pregnancy. Archives of women's mental health, 17(4), 311-315. doi: 10.1007/s00737-013-0397-0

[15] Suponeva, N. A., Bakulin, I. S., Pojdasheva, A. G., \& Piradov, M. A. (2017). Безопасность транскраниальной магнитной стимуляции: обзор международных рекомендаций и новые данные [Safety of transcranial magnetic stimulation: a review of international guidelines and new evidence]. Heрвно-мышечные болезни - Neuromuscular Diseases, 7(2), 21-36.

[16] Thompson, A. J., Baranzini, S. E., Geurts, J., Hemmer, B., \& Ciccarelli, O. (2018). Multiple sclerosis. The Lancet, 391(10130), 1622-1636. doi: 10.1016/s0140-6736(18)30481- 